\title{
Whereto mental health reform in Australia: is anyone listening to our independent auditors?
}

\section{Independent audits find consistent evidence of failure across Australia's mental health system}

T here is widespread agreement that Australia's mental health system is in critical need of reform. In a move that has left many in the mental health sector wondering if they were trapped in a rerun of Groundhog day, the Australian Government recently charged the National Mental Health Commission with undertaking a mental health review to investigate the gaps and duplications in, and effectiveness of, Australia's mental health system.

This review followed in the wake of a long series of national and state inquiries and reviews of the mental health sector in Australia dating back to the Burdekin Report in 1993, which provided the impetus for a national mental health reform agenda. ${ }^{1}$ The findings of these reviews point to the continuing failure of successive governments to build the communitybased model of care promised after the closure of stand-alone psychiatric institutions.

\section{"It is vital that new investment is directed to reorganising and reforming, rather than perpetuating a dysfunctional system"}

An additional important source of information about the mental health sector is available in the many independent audits undertaken by statutory and similar authorities. In 2013, as part of the Obsessive hope disorder report, we conducted a systematic qualitative review of all such audits undertaken in Australia between 2006 and 2013. ${ }^{2}$ Several themes emerged across the health care spectrum (Appendix). These included inadequate access to services, inadequate interagency cooperation and continuity of care, human rights concerns, gaps in training, and absence of monitoring and surveillance. The same issues were identified by Burdekin. ${ }^{1}$

\section{Gaps in service access}

We noted gaps in community mental health awareness and primary prevention programs, and inadequate access to community-based mental health care. There were also inadequate community and hospital services in justice settings, rural and remote regions; a paucity of specialised community, crisis and hospital treatment for young people; inadequate

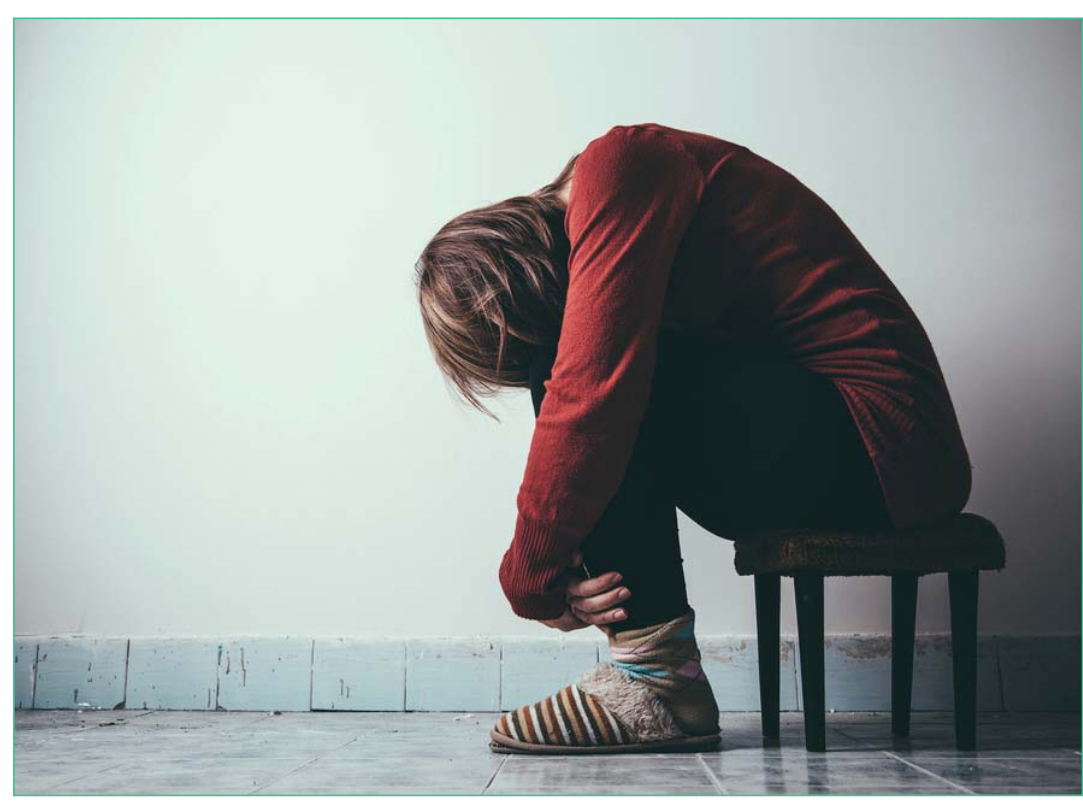

specialised community and hospital treatment for older people; and a lack of supported accommodation for people with a mental illness.

One driver of insufficient access was the inequitable distribution of the workforce across hospital and community sectors. A second was the exclusion of people from care unless they were in crisis. As noted by one young person: "Telling someone who has an eating disorder [ED] that they have not yet lost enough weight to be seen by an ED clinic is BAAAAAAAAD" (p. 50). ${ }^{3}$

Another driver of inadequate access to care was a reliance on diagnosis rather than need in allocating services. Further, uneven access to care resulted from managing demand by using strategies that were not based on need. One such strategy was to cap the number of referrals to the Access to Allied Psychological Services program that individual practitioners were permitted to provide. ${ }^{4}$

\section{Inadequate interagency cooperation and continuity of care}

1 National Institute for Mental Health Research, Canberra, ACT. 2 Connetica, Caloundra, QLD.

3 Brain and Mind Research Institute, Sydney, NSW.

Kathy.Griffiths@ anu.edu.au

doi: 10.5694/mjal4.01034
Mental health care was also compromised by poor cooperation between agencies and inadequate continuity of care. This was evident across the care spectrum from prevention to accommodation, with agencies failing to follow up, share information, integrate services, agree on the division of responsibilities and develop consistency in entry criteria. For example, community mental health 
teams in Western Australia had shared only 19\% of care plans with other professionals, such as general practitioners. ${ }^{5}$ More than one audit implicated poor interagency communication in the subsequent deaths of young people.

\section{Human rights concerns}

The audits reported human rights concerns among some crisis and inpatient services and denial of equitable access to supported accommodation. Examples included:

- Consumers who were not a threat to others being transferred to hospital in police vans instead of ambulances - contrary to service protocol;

- Crisis assessment and treatment team (CATT) members requesting detention of intoxicated consumers in police cells - in contravention of the relevant charter of human rights;

- Consumers not being informed of their rights in hospital;

- Wrongful shackling of prisoners with a mental illness in hospital;

- Perceived organisational bias directed towards forensic inpatients;

- Denial of privacy during inpatient consultations — in violation of the national standards for mental health privacy legislation; and

- Voluntarily admitted consumers being placed in locked wards.

Further, there are reports that people with a mental illness have been systematically denied their rights to supported accommodation. In particular, in New South Wales, supported accommodation in the disability sector was not available to people with a primary diagnosis of a mental illness. The NSW Ombudsman described this situation as a denial of "fundamental rights under mental health and disability legislation" (Foreword). ${ }^{6}$ He reported estimates that suggest that between $30 \%$ and $60 \%$ of current psychiatric inpatients could be discharged if suitable supported accommodation and community supports were available (p. 47). ${ }^{6}$ The responsible government department responded that if psychiatric patients were allocated the places within current resources, other people with disability would be denied places. The Ombudsman concluded that "it is unacceptable to trade-off the rights of people with psychiatric disability against those of others" (p. 67). ${ }^{6}$

\section{Groups who were disadvantaged}

Some groups were particularly disadvantaged. Groups with particular unmet need included those in the forensic system, people from rural areas, youth and older people, Aboriginal and Torres Strait Islander Australians, those from a culturally and linguistically diverse background, veterans, and children at risk.

Disadvantage was particularly evident in forensic contexts. One auditor reported the case of a woman with schizophrenia whose medication was discontinued on her arrival in prison. ${ }^{7}$ The treatment could not be resumed until she was assessed by a prison psychiatrist 12 days later. ${ }^{7}$ Another auditor reported an initial refusal by juvenile justice staff to allow a resident to receive urgent, prescribed psychiatric medication from a CATT member. ${ }^{8}$

\section{Gaps in training}

Action was consistently recommended across services and sectors to rectify gaps in training. Examples of the training required included de-escalation training for CATT members and police including those operating tasers, specialist training in the mental health of older people, mental health literacy training for social security and immigration staff, practical training for housing sector staff in strategies for supporting people with a mental illness, training for health staff in negotiating the housing system, and exposure of police to consumer perspectives.

\section{Inadequate monitoring and surveillance}

Many audits criticised the lack of appropriate data collection and monitoring by services and programs. For example, the NSW Audit Office found that it was not possible to determine accurately the size of the NSW mental health workforce due to inadequate data. ${ }^{9}$

\section{Limitations, accountability and the way forward}

A limitation of our review is that its conclusions were derived largely from individual audits and reviews of services in particular jurisdictions. Audits can lack the rigour of health services research, a field that itself is neglected.

However, auditors can obtain information and data that researchers cannot. Moreover, the consistency in the gaps that emerged together with the findings from previous enquiries and contemporary feedback from consumers ${ }^{10}$ suggest that the areas identified require action at a systemic level. The need to improve access to services and accommodation, continuity of care, training, and cooperation across agencies and services, and to engage with human rights, is clear, as is the need to increase service access for specific groups, particularly those in forensic environments.

Why do problems with the mental health system persist? There are several reasons. Despite the wealth of data in these audit reports and their potential role in mental health reform, there are typically 
no accountability mechanisms to ensure that the responsible lead authorities change their practices to deal with the recommendations in these audits. Moreover, there are no formal mechanisms by which the findings and recommendations can be incorporated into national and state mental health plans or the processes of the National Mental Health Commission.

Independent evaluations of the National Mental Health Plans have repeatedly pointed to the need to strengthen accountability, ${ }^{11}$ and others have argued that the failure to develop robust monitoring and reporting contributes to the failure to deliver mental health reform in Australia. ${ }^{12}$ Governments need to consider how agencies can be held accountable if they fail to implement changes recommended by auditors. Further, we need to develop formal processes by which the findings of independent audits are reviewed systematically and the outcomes made available in an accessible form to the Australian Health Ministers' Advisory Council, the Council of Australian Governments, and to consumers and carers.

It is vital that new investment is directed to reorganising and reforming, rather than perpetuating a dysfunctional system. Innovative approaches are required - for example, information technology has the potential to deliver critical preventive interventions that cost-effectively reduce the prevalence of mental illness, to increase access to evidence-based treatments, and to facilitate service integration and seamless data collection. Structural stigma underpins discriminatory policies and funding allocations that adversely affect those with a mental illness. Multilevel stigma reduction initiatives and awareness raising are needed to reduce stigma at all levels in our society including among policymakers and decisionmakers.

If Australia is ever to escape from Groundhog day, it is imperative that we move from audits and government reviews to the coordinated implementation of solutions.

Acknowledgements: Kathleen Griffiths is supported by Australian National Health and Medical Research Council Research Fellowship (grant 1059620).

Competing interests: No relevant disclosures.

Provenance: Not commissioned; externally peer reviewed.

A podcast and video interview with Professor Kathleen Griffiths are available from the multimedia section at www.mja.com.au/multimedia 
1 Human Rights and Equal Opportunity Commission. Human rights and mental illness: report of the National Inquiry into the Human Rights of People with Mental Illness. Canberra: AGPS, 1993.

2 Griffiths KM, Carron-Arthur B, Mendoza J. A systematic review of independent audits of mental health and associated services by statutory and related authorities. In: Mendoza J, Bresnan A, Rosenberg S, et al, editors. Obsessive hope disorder: reflections on 30 years of Australian mental health reform and visions for the future. Caloundra: Connetica, 2013.

3 Commissioner for Children and Young People Western Australia. Report of the Inquiry into the mental health and wellbeing of children and young people in Western Australia. Perth: CCYPWA, 2011. http://www.ccyp.wa.gov.au/files/ MentalWellbeingInquiry/CCYP\%20Mental\%2OHealth\%20 Inquiry\%20-\%20Report\%20to\%20Parliament.pdf (accessed Nov 2014).

4 Australian National Audit Office. Administration of the Access to Allied Psychological Services Program. (The Auditor-General Audit Report No. 51 2010-11 Performance Audit.) Canberra: Australian Government Department of Health and Ageing, 2011. http://www.anao.gov.au/ / media/Uploads/Audit\%20Reports/2010\%2011/201011\%20 Audit\%20Report\%20No51.pdf (accessed Feb 2015).

5 Auditor General Western Australia. Adult community mental health teams: availability, accessibility and effectiveness of services. Perth: AGWA, 2009. https://audit.wa.gov.au/wpcontent/uploads/2013/05/report2009_10.pdf (accessed Nov 2014).

6 New South Wales Ombudsman. Denial of rights: the need to improve accommodation and support for people with psychiatric disability. Sydney: NSW Ombudsman, 2012. https://www.ombo.nsw.gov.au/_data/assets/ pdf_file/0010/7489/SR_Denial_of_Rights_Mental_Health_ Report_Web.pdf (accessed Nov 2014).

7 New South Wales Ombudsman. Report of reviewable deaths in 2010 and 2011 volume 2: deaths of people with disabilities in care. Sydney: NSW Ombudsman, 2013. https://www.ombo. nsw.gov.au/_data/assets/pdf_file/0007/9448/ReviewableDeaths-Disability-Death.pdf (accessed Nov 2014).

8 ACT Human Rights Commission. The ACT youth justice system 2011: a report to the ACT Legislative Assembly by the ACT Human Rights Commission. Canberra: ACT HRC, 2011. http://www.hrc.act.gov.au/content.php/content.view/id/251 (accessed Nov 2014).

9 Audit Office of New South Wales, Mental Health Workforce: NSW Health. Sydney: AONSW, 2010. http://www.audit. nsw.gov.au/ArticleDocuments/142/210_Mental_Health_ Workforce.pdf.aspx?Embed=Y (accessed Feb 2015).

10 Mendoza J, Bresnan A, Rosenberg S, et al. Obsessive Hope Disorder: Reflections on 30 years of mental health reform in Australia and visions for the future. Caloundra: Connetica, 2013.

1 Curie C, Thornicroft G. Summative evaluation of the National Mental Health Plan 2003-2008. Canberra: Australian Government Department of Health and Ageing, 2008. http:// www.health.gov.au/internet/main/publishing.nsf/Content/ mental-pubs-s-sumplan03 (accessed Nov 2014).

12 Rosenberg SP, Mendoza J, Russell L. Well meant or well spent? Accountability for $\$ 8$ billion of mental health reform. Med J Aust 2012; 196: 159-161. 